\title{
Sponsor Defined Group Code
}

National Cancer Institute

\section{Source}

National Cancer Institute. Sponsor Defined Group Code. NCI Thesaurus. Code C90456.

Symbol(s) assigned by a sponsor to a collection of items. 